\title{
Development of a Multidimensional Proteomic Approach to Detect Circulating Immune Complexes in Cattle Experimentally Infected With Mycobacterium bovis
}

\author{
Syeda A. Hadi ${ }^{1}$, Wade R. Waters ${ }^{2}$, Mitchell Palmer ${ }^{2}$, Konstantin P. Lyashchenko ${ }^{3}$ and \\ Srinand Sreevatsan ${ }^{\text {* }}$ \\ ${ }^{1}$ Department of Pathobiology and Diagnostic Investigation, College of Veterinary Medicine, Michigan State University, East \\ Lansing, MI, United States, ${ }^{2}$ National Animal Disease Center, Agricultural Research Service, United States Department of \\ Agriculture, Ames, IA, United States, ${ }^{3}$ Chembio Diagnostic Systems Inc., Medford, NY, United States
}

OPEN ACCESS

Edited by:

Adrian Allen,

Agri Food and Biosciences Institute,

United Kingdom

Reviewed by:

Simon Babayan,

University of Glasgow,

United Kingdom

Kieran G. Meade,

Teagasc, The Irish Agriculture and

Food Development Authority, Ireland

*Correspondence:

Srinand Sreevatsan

sreevats@msu.edu

Specialty section:

This article was submitted to

Veterinary Infectious Diseases,

a section of the journal

Frontiers in Veterinary Science

Received: 14 February 2018

Accepted: 06 June 2018

Published: 26 June 2018

Citation:

Hadi SA, Waters WR, Palmer M, Lyashchenko KP and Sreevatsan S

(2018) Development of a

Multidimensional Proteomic Approach

to Detect Circulating Immune

Complexes in Cattle Experimentally

Infected With Mycobacterium bovis.

Front. Vet. Sci. 5:141

doi: 10.3389/fvets.2018.00141
Objective: To evaluate a high-resolution method to identify pathogen-specific biomarkers in serum of calves infected with Mycobacterium bovis.

Methods: Serum samples from four calves infected with $M$. bovis were collected before and after infection at weeks 9, 14, 15, 31, and 36. Immune-complex-associated mycobacterial antigens in the serum were enriched using an immunochromatography method termed, dual path platform (DPP). All regions of antigen capture zones, that consisted of monospecific rabbit polyclonal antibodies raised against $M$. tuberculosis lysates, on DPP strips were excised and analyzed by multidimensional proteomics. The resulting proteins were then passed through 4 rigorous peptide quality filters-false-hits, decoys, non-M. tuberculosis complex proteins were all removed followed by individual quality check of those remaining. Peptides were then checked on NCBI's BLASTp for M. tuberculosis complex specificity.

Results: Proteins in 2 of the animals passed the multipronged-highly stringent peptide quality analysis. Animal\#54 had 7 unique $M$. tuberculosis complex proteins at week 14 post-infection, while animal\#56 had 4 at week 36 post-infection along with 1 immunoglobulin.

Conclusion: M. tuberculosis complex -specific peptides identified in this study were identified in 2 animals and at 2 separate time points post infection. Further studies with better enrichment protocols and using larger sample sizes and replications are required to develop a TB-specific diagnostic tool for bovine tuberculosis.

Keywords: bovine tuberculosis, dual path platform, immune-complexes, mass-spectrometry, Mycobacterium bovis, mycobacteria, biomarkers, diagnostics

\section{INTRODUCTION}

Mycobacterium bovis causes tuberculosis primarily in cattle but it is also zoonotic. Transmission to humans occurs through close contact with infected animals or via consumption of contaminated animal products (e.g., unpasteurized milk or dairy products) (1-3). The primary screening test used in the field is tuberculin-based skin test which is time-consuming, labor intensive and associated 
with low sensitivity and variable specificity. Variability in specificity is caused by species differences and technique being used $(4,5)$. Ultimately a false-positive can lead to a considerable financial burden on farmers deterring control measures. Thus, there is a need for highly specific rapid field tests that are cost effective.

Immune complexes are formed by the non-covalent binding of antigens with antibody molecules circulating real-time (6). Lyashchenko et al. (7), reported the presence of Mycobacterium specific immune complexes in cattle experimentally infected with $M$. bovis detectable by the dual-path platform (DPP) assay that utilizes polyclonal antibodies against $M$. tuberculosis wholecell antigens. This provided an unprecedented opportunity to interrogate $M$. tuberculosis complex-specific antigens enriched by polyclonal tuberculosis-specific antibodies using high resolution technique of liquid chromatography followed by dual mass-spectrometry (LC-MS/MS). LCMS/MS can detect proteins at abundances as low as $10^{-15}$ moles, thereby enabling discovery of circulating in infected animals. In the present study, high-resolution multidimensional mass spectrometry analysis of the DPP-captured immune complexes was evaluated for its ability to identify the captured $M$. bovis-specific peptides that may aid in the development of a highly accurate tuberculosis diagnostics for animals and humans.

\section{MATERIALS AND METHODS}

Seven Holstein calves obtained from a TB-free herd in IA and housed in a biosafety level 3 (BSL-3) facility at the National Animal Disease Center, Ames, IA were infected at 11 months of age with $8 \times 10^{3} \mathrm{CFU}$ of virulent $M$. bovis (95-1315; USDA Animal Plant and Health Inspection Service [APHIS] designation) by aerosol. This strain of $M$. bovis was isolated from a white-tailed deer in Michigan, USA. Animals were sampled for serum at multiple time points pre- and post-infection over the next 11.5 months at which point they were euthanized $(7,8)$. Necropsy of all the calves revealed presence of gross lesions in multiple organs specific to bovine tuberculosis and bacterial culturing from infected tissues confirmed the presence of $M$. bovis in all 7 animals infected.

In this pilot study we focused on 4 out of the 7 calves present in the original study (7), since they had the highest levels of circulating immune complexes to increase the probability of biomarker discovery. Pre- and post-inoculation samples collected at weeks $9,14,15,31$, and 36 were used to identify mycobacterial specific peptides. To characterize the circulating immune complexes-associated with $M$. tuberculosis complex, a rapid DPP-Ag assay was performed (Figure 1). The DPP antigen capture zone (test line) was coated with rabbit polyclonal antibodies raised against $M$. tuberculosis whole-cell lysate to enable capture of mycobacterial antigen-antibody complexes $(7,8)$. Pre-infection (baseline) sera from these four animals served as negative controls. Triplicates of each time points from every animal were made pre and post-infection (which summed up to 27 DPP-Ag assay strips for analysis) for each week $0,9,14,31$ and 36 . A $50 \mu \mathrm{L}$ aliquot of serum sample was placed on three independent DPP-Ag strips for each time-point, to allow for antigen enrichment of molecules on the capture zone, which were then processed as one single sample to allow for maximum enrichment, enhanced sensitivity, efficient use of the LC-MS/MS and improved proteomics profile generation.

The immune-complex capture zone of $2 \mathrm{~mm}$ width was excised and analyzed by LC-MS/MS analysis performed at University of Minnesota's Center for Mass Spectrometry and Proteomics (CMSP). Triplicates of DPP-assays for every animal were pooled for analysis. A region $2 \mathrm{~mm}$ upstream of the antigen capture zone (or the DPP test line) was also analyzed by LCMS/MS. The enormous volume of peptide data generated by LCMS/MS was passed through a series of stringent filters before the final candidates were considered.

First, PEAKS (Bioinformatics Solutions Inc.) software was used to query peptides generated in each triplicate-pooledsample through LC/MS-MS against a database that included all documented peptides from M. tuberculosis Complex, cattle and rabbit proteins. These results were then analyzed by Scaffold (version Scaffold_4.7.5, Proteome Software Inc., Portland, OR) to validate all $\mathrm{MS} / \mathrm{MS}$ based peptide identifications and to allow combined visualization of all sample results. All identified peptides were compared against a decoy database (generated in Scaffold_4.7.5), consisting of randomized peptide sequences, to remove any spurious hits. Second, any protein that matched against the decoy database, was removed from further analysis. We focused only on the M. tuberculosis complex proteins because they offer highest possible specificity for bovine tuberculosis diagnostics. The third filter was based on an individual quality check of the proteins with in Scaffold. Peptide identifications were accepted in Scaffold if they could be established at greater than $95.0 \%$ probability by the Peptide Prophet algorithm (9) with Scaffold delta-mass correction. Protein identifications were accepted if they could be established at greater than $95.0 \%$ probability and contained at least 2 identified peptides. Proteins that contained similar peptides and could not be differentiated based on MS/MS analysis alone were grouped to satisfy the principles of parsimony. Peptides and proteins that were selected in the third filter had percent probabilities varying from 74 to $100 \%$. The fourth and the last filter was the identification of M. tuberculosis complex specificity using the National Center for Biotechnology Information (NCBI)'s non-redundant database BLASTp (basic local alignment search tool for proteins) analysis where two aspects were investigated: (1) $E$-value $\left(<1 \mathrm{e}^{-10}\right)$ and (2) the species match of the peptides. If the proteins matched with any other bacteria other than $M$. tuberculosis complex, they were excluded from further consideration. Additionally, if any peptides had an $E$-value higher than $1 \mathrm{e}^{-10}$, which suggested that the species match was likely non-random, they were also removed from further consideration. This last filter was excessively stringent as it eliminated most of peptide hits discovered after decoy database search. Some of the peptides eliminated may still be useful in a future validation study. 
The same pipeline was followed for identifying cattle specific immunoglobulins, where immunoglobulins were passed through all the filters described for M. tuberculosis complex proteins. Additionally, the proteins that overlapped between pre-infection and post-infection test-lines were excluded as it suggested that they were not associated with the $M$. bovis infection, rather existed in the background.

\section{RESULTS AND DISCUSSION}

The peptides generated from LC-MS/MS analysis resulted in identification of 26,945 proteins. Forty-nine percent of these were eliminated after the decoy database search. Of these, $3.73 \%$ were identified with the $M$. tuberculosis complex repertoire, $26.02 \%$ proteins were of host (bovine) origin and $21.35 \%$ were of leporine origin. DPP strips of all post-infection samples, except at week 31, had M. bovis proteins. After analysis, 11 $M$. tuberculosis complex-specific proteins were identified in two M. bovis-infected animals (Table 1). At week 14 (postinfection) serum from animal \#54 showed 7 proteins that corresponded to peptides in $M$. tuberculosis complex with a BLAST E-value lower than $1 \mathrm{e}^{-10}$ (Table 2). At week 36 post-infection, serum of animal \#56 had 4 proteins that corresponded to M. tuberculosis complex with an E-value lower than $1 \mathrm{e}^{-10}$ (Table 2).

At week 14 post-infection in animal \#54 polyketide synthase was detected, which plays a role in the growth of the bacteria and is considered a potential virulence factor (10). The detection of this protein at such an early stage in $M$. bovis infection agrees with other studies $(11,12)$ where polyketide synthase was detected through different techniques but at similar time points. Lamont et al. (11), showed that polyketide synthase can be used as a useful marker for detecting $M$. bovis infection in a multi-cut off fashion, based on the prevalence of the disease.

Killer cell immunoglobulin-like receptor $\left(1 \mathrm{e}^{-18}\right)$ in animal \#56 at week 36 corresponded to cattle (Bos taurus) specific immunoglobulin, alone passed all analysis filters. Even though pre-infection DPP-assays from all 4 animals were pooled together to enhance the probability of capturing all mycobacterial circulating immune complexes at base-line to compare them with proteins detected post-infection, no immune-complexes were detected at base-line.

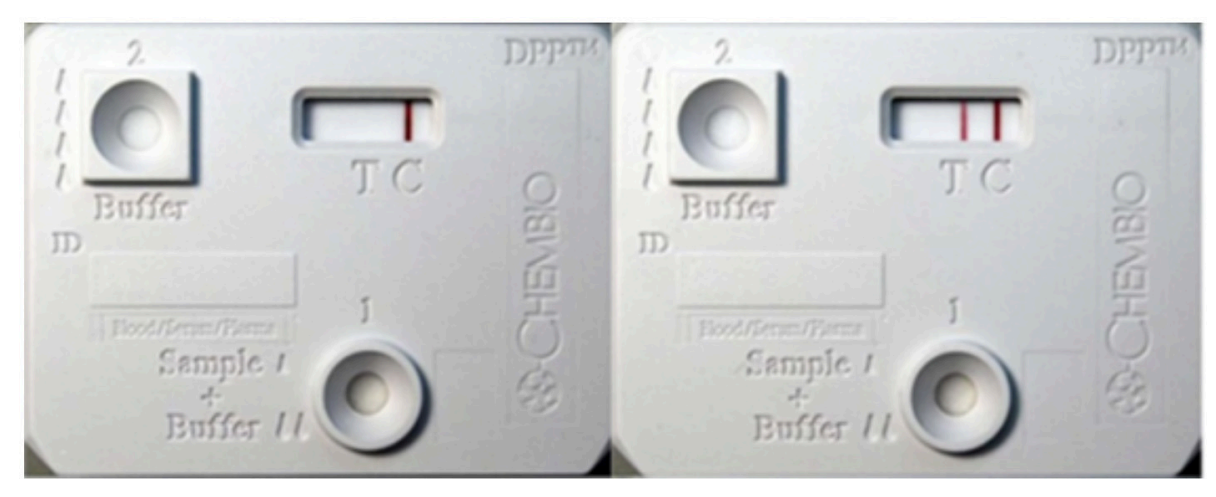

FIGURE 1 | Dual-path platform assay kit showing positive and negative controls. Dual-path platform assay was used to detect circulating antigen-antibody complexes in calves infected with Mycobacterium bovis. The rabbit polyclonal antibodies immobilized on the test line(T) acted as the capture reagent for the circulating immune-complexes in the infected animal's serum as well as signal detector when coated onto nano-gold-particles. DPP strip case: Left: Negative Control (serum from uninfected animals), Right: Positive control.

TABLE 1 | Enumeration of pathogen-derived proteins detected by mass spectrometry from DPP-Ag assay strips processed with serum samples from cattle experimentally infected with Mycobacterium bovis.

\begin{tabular}{|c|c|c|c|c|c|c|c|}
\hline \multirow[t]{2}{*}{ Animal ID } & \multicolumn{3}{|c|}{ Pre-infection } & \multicolumn{3}{|c|}{ Mycobacterium bovis infection } & \multirow[b]{2}{*}{$\begin{array}{c}\text { Cattle specific } \\
\text { immunoglobulins }\end{array}$} \\
\hline & $\begin{array}{l}\text { DPPAg } \\
\text { result }^{a} \text { ) }\end{array}$ & $\begin{array}{l}\text { Mycobacterium } \\
\text { bovis proteins } \\
\text { identified }^{b}\end{array}$ & $\begin{array}{l}\text { Cattle specific } \\
\text { immunoglobulins }\end{array}$ & $\begin{array}{c}\text { Week } \\
\text { post-inoculation }\end{array}$ & $\begin{array}{l}\text { DPP-Ag } \\
\text { result }^{\mathrm{a}}\end{array}$ & $\begin{array}{l}\text { Mycobacterium } \\
\text { bovis proteins } \\
\text { identified }\end{array}$ & \\
\hline 51 & 0 & 0 & 0 & 9 & 124 & 0 & 0 \\
\hline \multirow[t]{2}{*}{54} & 0 & 0 & 0 & 14 & 788 & 7 & 0 \\
\hline & & & & 15 & 772 & 0 & 0 \\
\hline 56 & 0 & 0 & 0 & 36 & 485 & 4 & 1 \\
\hline 57 & 0 & 0 & 0 & 31 & 447 & 0 & 0 \\
\hline
\end{tabular}

${ }^{a} D P P$ reader data (reflectance) in relative light units obtained as described (7).

${ }^{b}$ Pooled DPP-Ag strips processed with pre-infection sera from four calves. 
TABLE 2 | List of Mycobacterium tuberculosis complex-specific high confidence proteins at week 14 and week 36 and cattle immunoglobulin at week 36 that passed exclusion criteria.

\begin{tabular}{ll}
\hline $\begin{array}{l}\text { Mycobacterium tuberculosis } \\
\text { complex proteins at wk14 }\end{array}$ & $\begin{array}{l}\text { Peptide sequences used for BLASTp } \\
\text { analysis }\end{array}$ \\
\hline Acyltransferase & $\begin{array}{l}\text { QDGSASYDAAVR- } \\
\text { MLKAGELVGVYPEATISR }\end{array}$ \\
Esterase & VFGAADPR-FACWVAFASMFPGR \\
LLM class F420-dependent & QKDYDEYGYR-FGTAGSRLDDLAAPLPR \\
oxidoreductase & \\
Transposase, partial & MDPTEDQARALAR-VTGIGTVKPSLRVLR \\
Transcriptional regulatory protein & FGILGPLEISAGFRSLPLGTPK- \\
embr2 & SPLGRLPLR \\
Hypothetical protein Mb3478 & GASPATAAR- \\
& LPPALNPDDADALPTTDRLTTR \\
Polyketide synthase & DGDRVLAIVR-LVDAPLPSWTHRTLMLSR- \\
& MFNSLGIQYGPAFSGLVAVHTAR- \\
& LFWTRSAASVLPSDLANLEQAGMR
\end{tabular}

Mycobacterium tuberculosis complex proteins at wk36

Peptide sequences used for BLASTp analysis

Helicase helz

Hypothetical protein Mb1791

Hypothetical protein Mb2390c

Chromosome partition protein

Smc

Cattle Immunoglobulin at

week 36

Peptide sequences used for BLASTp analysis

PREDICTED: killer cell

GEMLTSGHAPADFVIGPMTLASAGTYR

immunoglobulin-like receptor,

three domains, long cytoplasmic

tail, 2 isoform $\times 2$

The proteins that did not comply with exclusion criteria were removed such as nonMycobacterium tuberculosis complex proteins, decoy proteins, low quality proteins and proteins that did not identify with Mycobacterium tuberculosis complex when NCBl's non-redundant database BLASTp (basic local alignment search tool for proteins) analysis was used. The same pipeline was used to identify cattle immunoglobulins. The hyphen represents the space given in NCBl's BLASTp search that allowed to account for the presence of other amino acids in between the peptides that formed the proteins.

The panel of mycobacterial proteins and cattle specific immunoglobulin reported in the present study may be specific to the infection stage at which they were detected, as the proteins seen at week 14 did not overlap with those detected at week 36 post infection. Alternatively, since these distinct proteins sets were found in two different animals, they could be a result of animal-to-animal variation in host response to the infection.

A major limitation of our study was sample size. Since the LC/MS-MS analysis itself was expensive and limited amounts of infected animal sera were available, multiple replications on the same animals were not possible. Additionally, multiple logistical and financial issues precluded us working with larger sample sizes: (1) working with agricultural animals for experimental infection with a BSL-3 pathogen and (2) Expenses associated with a BSL-3 cost, animal costs as well as personnel. Thus, to compensate for this limitation triplication of every animal's sample was performed.

Furthermore, the use of an antiserum derived against M. tuberculosis may have compromised specificity of our approach to detect $M$. bovis specific antigens, although these organisms are genetically very closely related. Future analysis though should include multiple replications of experimental infections followed by DPP assay and LC-MS/MS to discover $M$. bovis specific peptides in a reproducible and accurate fashion. Furthermore, a field validation on multiple exposure levels in outbreaks would be necessary for this technology to be applicable in routine bovine TB diagnostics.

In conclusion, the panel of 11 proteins reported in this study are specific to $M$. bovis. Further studies with more robust enrichment methods and larger sample sizes would be required to confirm these findings. Further validation of the identified circulating immune-complexes in naturally infected cattle would enable us to effectively and broadly apply the DPP technology in field.

\section{ETHICS STATEMENT}

All studies were approved by the National Animal Disease Center Animal Care and Use and Institutional Biosafety committees and performed under appropriate project licenses within the conditions of the Animal Welfare Act.

\section{AUTHOR CONTRIBUTION}

WW and MP conducted the animal infection and testing studies. KL developed the DPP lateral flow devices. SS and $\mathrm{SH}$ developed protocols for extraction of total proteins from DPP devices, performed proteomics and data analysis. WW, SH, KL, and SS wrote the paper.

\section{FUNDING}

The project was supported by Grand Challenges - UMN (Interspecies transmission of tuberculosis in Uganda) and USDANIFA grants funded to SS and to KL (Award No. 2016-3361025688).

\section{ACKNOWLEDGMENTS}

We would like to thank University of Minnesota's Center of Mass Spectrometry and Proteomics, especially Mr. Todd W. Markowski for his input and guidance. 


\section{REFERENCES}

1. Hlavsa MC, Moonan PK, Cowan LS, Navin TR, Kammerer JS, Morlock GP, et al. Human Tuberculosis due to Mycobacterium bovis in the United States, 1995-2005. Clin Infect Dis. (2008) 47:168-75. doi: 10.1086/589240

2. OIE (2015). Manual of Diagnostic Tests and Vaccines- Chapter 2.4.6-Bovine Tuberculosis. Paris: OIE. Available online at: www.oie.int/standard-setting/ terrestrial-manual/access-online

3. Wilkins MJ, Meyerson J, Bartlett PC, Spieldenner SL, Berry DE, Mosher LB, et al. Human Mycobacterium bovis infection and bovine tuberculosis outbreak, michigan, 1994-2007. Emerging Infect Dis. (2008) 14:657-66. doi: 10.3201/eid1404.070408

4. Cousins DV, Florisson N. A review of tests available for use in the diagnosis of tuberculosis in non-bovine species. Rev Sci Tech Off Int Epiz (2005) 24:1039-59. doi: 10.20506/rst.24.3.1635

5. De la Rua-Domenech R, Goodchild AT, Vordermeier HM, Hewinson RG, Christiansen $\mathrm{KH}$, and Clifton-Hadley RS. Ante mortem diagnosis of tuberculosis in cattle: a review of the tuberculin tests, gamma-interferon assay and other ancillary diagnostic techniques. Res Vet Sci. (2006) 81:190-10. doi: 10.1016/j.rvsc.2005.11.005

6. De Rycke L, Peene I, Hoffman IEA, Kruithof E, Union A, Meheus L, et al. Rheumatoid factor and anti-citrullinated protein antibodies in rheumatoid arthritis: diagnostic value, associations with radiological progression rate, and extra articular manifestations. Ann Rheum Dis. (2004) 63:1587-93. doi: 10.1136/ard.2003.017574

7. Lyashchenko KP, Greenwald R, Sikar-Gang A, Sridhara AA, Johnathan A, Lambotte P, Waters WR. Early detection of circulating antigen and igm-associated immune complexes during experimental Mycobacterium bovis infection in cattle. Clin Vaccine Immunol. (2017) 24:e00069-17. doi: 10.1128/CVI.00069-17

8. Waters WR, Vordermeier HM, Rhodes S, Khatri B, Palmer MV, Maggioli MF, et al. Potential for rapid antibody detection to identify tuberculous cattle with non-reactive tuberculin skin test results. BMC Vet Res. (2017) 13:164. doi: 10.1186/s12917-017-1085-5

9. Keller A, Nesvizhskii AI, Kolker E, and Aebersold R. Empirical statistical model to estimate the accuracy of peptide identifications made by MS/MS and database search. Anal Chem. (2002) 74:5383-92. doi: 10.1021/ac025747h

10. Forrellad MA, Klepp LI, Gioffré A, García JSY, Morbidoni HR, Santangelo MP, Bigi F. Virulence factors of the Mycobacterium tuberculosis complex. Virulence (2013) 4:3-66. doi: 10.4161/viru.22329

11. Lamont EA, Janagama HK, Ribeiro-Lima J, Vulchanova L, Seth M, and Yang M. Circulating Mycobacterium bovis peptides and host response proteins as biomarkers for unambiguous detection of subclinical infection. J Clin Microbiol. (2014) 52:536-43. doi: 10.1128/JCM. 02433-13

12. Wanzala SI, Palmer MV, Waters WR, Thacker TC, Carstensen M, Travis DA, et al. Evaluation of pathogen specific biomarkers for the diagnosis of tuberculosis in white-tailed deer (Odocoileus virginianus). Am J Vet Res. (2017) 78:729-34. doi: 10.2460/ajvr.78.6.729

Conflict of Interest Statement: KL is employed by Chembio Diagnostic Systems, Inc.

The remaining authors declare that the research was conducted in the absence of any commercial or financial relationships that could be construed as a potential conflict of interest.

Copyright (c) 2018 Hadi, Waters, Palmer, Lyashchenko and Sreevatsan. This is an open-access article distributed under the terms of the Creative Commons Attribution License (CC BY). The use, distribution or reproduction in other forums is permitted, provided the original author(s) and the copyright owner are credited and that the original publication in this journal is cited, in accordance with accepted academic practice. No use, distribution or reproduction is permitted which does not comply with these terms. 